\title{
Imagens da Cidade: um Exercício sobre Representações Sociais
}

\section{City Images: an Exercise in Social Representation}

\author{
Ana Lucia Lucas Martins \\ Universidade Federal Rural do Rio de Janeiro \\ Rio de Janeiro, Brasil
}

\begin{abstract}
Resumo: O artigo aborda o cinema percebido como um território dotado de características sociais, geográficas e culturais próprias cujos símbolos e imagens, em um cotejo com fontes sociológicas, literárias e imagéticas, permitem uma representação da metrópole de modo a considerar a ideia de "crise" da sociedade urbana. Na experiência de constituição da metrópole é examinada a singularidade da cidade brasileira em dois momentos: a cidade da tradição ibérica e "a cidade desenvolvimentista".
\end{abstract}

Palavras-chave: cidade, imagens, representações, cinema.

\begin{abstract}
This article treats film as a territory with social, geographical and cultural characteristics whose symbols and images involving sociological, literary and imagery sources permits a representation of the metropolis which elucidates the "crisis" of urban society. The singularity of Brazilian cities in the experience of constituting the metropolis is considered in two moments: the city in Iberian tradition and in "city development".
\end{abstract}

Keywords: city, image, representation, cinema.

\section{A cidade}

"Agora os objetos me percebem." - Paul Klee (apud PAUL VIRILIO, 1994 - A máquina de visão)

A cidade tradicionalmente pensada a partir de modelos e categorias que serviram para compreender a cidade industrial do século XIX apresenta uma nova complexidade social a partir da influência de rápidas transformações técnico-científicas.

A ideia de uma "crise" da sociedade urbana tem aparecido em diagnósticos de uma literatura como a que trata do processo de globalização. A década de 70 do século XX foi assinalada como um momento de intensificação da crise urbana contemporânea. A passagem do fordismo para uma acumulação flexível (HARVEY, 1994, p.177) estaria propiciando uma "compressão do tempo-espaço" com consequências desorientadoras e disruptivas não só sobre as práticas político-econômicas, mas também sobre a vida social e cultural. ${ }^{1}$ Acena-se com um cenário de tempos de giro em aceleração e com

Professora do Departamento de História e Economia, martins.allu@gmail.com. 
transformações nos usos e significados dos espaços e do tempo, nas formas de pensar, sentir e agir nas metrópoles atuais. A experiência cotidiana dos indivíduos estaria golpeada por mudanças que alterariam formas de sociabilidade baseadas em valores ainda não impregnados na sua radicalidade pela ideia do volátil, do instantâneo, do fragmento.

Com o advento de uma organização social dominada pelos serviços e informação da abundância das comunicações rápidas, da imagem saturando o cotidiano e alterando as percepções dos indivíduos -, novas demandas descritivas e analíticas se colocam diante de uma abordagem da cidade do nosso tempo, cujas formas espaciais e sociais apresentam mutações velozes.

Se as afirmações anteriores parecem orientar de forma genérica reflexões sobre a realidade social contemporânea, no caso do Brasil, em que também os impactos daquela dinâmica se fazem presente, é possível um diagnóstico dos "aportes analíticos" que contribuam para a compreensão dos estudos sobre as metrópoles contemporâneas, em particular no que diz respeito aos vínculos entre "vida metropolitana e fragmentação". As reflexões são sugeridas a partir de temáticas diversas. ${ }^{2}$ A dificuldade de estabelecer conceitos capazes de operacionalizar uma compreensão da vida social contemporânea (SANTOS apud RIBEIRO,1994, p.149), das mudanças sociais decorrentes de impactos de novas transformações tecnológicas e da própria relação indivíduo e sociedade é constatada não só por aqueles que lidam mais diretamente com a problemática do urbano no campo das ciências sociais, mas estende-se a esferas diversas do pensamento social. ${ }^{3}$

O objetivo a que me proponho é, abordando algumas narrativas sobre cidades, explorar um tipo de perspectiva que aciona linguagens distintas para examinar experiências urbanas em contextos temporais e espaciais diversos. Essa perspectiva não se apresenta propriamente como uma novidade na medida em que, de certo modo, pode ser referida a uma tradição de "vocação pluralista" já presente em um dado momento das ciências sociais no Brasil (PEIRANO, 1991). Lançando mão de uma multiplicidade de saberes que tentam vislumbrar uma compreensão da metrópole atual, vou procurar construir um ponto de vista para um enquadramento futuro de questões. Textos literários, imagéticos, científicos apresentam-se em narrativas que se conjugam para um entendimento da metrópole cuja materialidade se dá em fluxos simultâneos que confundem nossa percepção.

\section{As Cidades Brasileiras: de um "Certo Oriente" ao Ocidente}

Que representações da cidade brasileira podem ser apreendidas e como elas se singularizam nessa experiência particular? Gilberto Freire (1985) assinala um momento importante de nossa formação urbana, quando a rua adquire prestígio. A partir de princípios do século XIX a rua deixa de ser o "escoadouro das águas servidas dos sobrados para ganhar dignidade e importância social". A iluminação pública lhe fornece o brilho outrora parco vindo das janelas dos sobrados. As posturas municipais se afirmam no sentido de limitar a arrogância da casa-grande na forma de sobrados. As ruas deixam de ser simples "caminhos a serviço das casas poderosas". Esse fenômeno de exteriorização se dá, portanto, em uma luta contra os espaços privados da família patriarcal. O trânsito, a dispersão se fazem apoiados na emergência desse novo espaço social. Nas ruas, nas praças, nas festas de igreja, no mercado, na escola, no carnaval, novas condições de 
comunicação descortinam uma situação social distinta daquela dos espaços íntimos. Nesse cenário da rua são grupos sociais complexos e díspares que estão em contato. A cidade diversificada aos poucos se torna intensa, em um impulso cinético de corpos e veículos. O ritmo da "passagem" se impõe. Mas de que forma? Nem as imagens de "caos e inferno" da Paris de Benjamim (1985) nem a "usina", retrato de Engels (1986) sobre Manchester com sua "massa de trabalhadores pobres e anônimos" se adéquam para definir a feição da cidade diante das transformações em curso. Tratando-se do Rio de Janeiro, quando lemos Memórias de um sargento de milícias, de M. A. de Almeida (s. d.), fica-nos a impressão de um ritmo particular. São os "remediados", gente de vidinha miúda que vive do ócio ao negócio de todo tipo de mercadoria, que circulam pelo espaço urbano.

O ar da colônia e a feição de um "certo oriente", características da cidade do século XVIII, também criam distinções em relação às cidades europeias. Ainda em G. Freire (Op. cit.) apreendemos a descrição de uma paisagem social cujo tom oriental evidenciava-se em um conjunto de usos, hábitos e costumes: a reclusão moura das mulheres, as sandálias, as fontes, a esteira, as cores das casas, dos palanquins, dos xales das mulheres, dos vestidos e das roupas. Os costumes ocidentais são impregnações mais ou menos recentes. A europeização tinge a paisagem social de preto e cinza. No contato com a "nova Europa", os tons empalidecem. A sobrecasaca preta, as cartolas pretas, as botinas pretas: "cores civilizadas, urbanas, burguesas em oposição às rústicas, às orientais, às africanas, às plebeias". A chegada do rei impôs esse ritmo às transformações. Com ele vieram estilos de vida e maravilhas do mundo moderno. O fascínio do urbano aporta na cidade. Novos costumes, novas tecnologias.

As descrições da cidade a partir do início do século XX vão estar próximas das experiências em curso nas cidades europeias. O automóvel, a luz elétrica, a fotografia, o cinematógrafo. A sofisticação das casas comerciais, em particular o comércio têxtil em que franceses e ingleses atuavam em um rico e luxuoso negócio, influenciava o gosto e os costumes dos habitantes da cidade. A metrópole passa pela sua mais importante renovação urbanística, sanitária e social. O "Rio civiliza-se", era o slogan da época. Diante das transformações e demandas em que uma nova filosofia financeira reclamava modelações não só do espaço físico, mas de hábitos, a imagem da cidade insalubre e insegura, ocupada por gente pobre vivendo em meio à precariedade, deveria ser transmutada em uma imagem de "plena credibilidade", a imagem do progresso. Sevcenko (1983) observa que a "Liga contra o Feio", criada pelo cronista Luis Edmundo em 1908, e a "Liga da Defesa Estética", por Coelho Neto em 1915, são reveladoras da identificação das elites urbanas com um mondo de vida chique e do otimismo com um cosmopolitismo aos moldes europeus (Op. cit., p.83).

João do Rio e Lima Barreto (1948) refletem de forma distinta a efervescência social e cultural da cidade. A realidade das ruas, da cidade oculta que vive à sombra dos desígnios do progresso, é retratada nas crônicas de João do Rio (MARTINS, s. d.). A cidade feia e miserável resiste aos códigos cultos da Belle Époque. Na sua ambiguidade, ora embevecido pelo progresso, ora consternado com o que vê - a destruição da velha cidade -, o cronista nos revela a linguagem das ruas, as atividades dos "miseráveis da arte", pintores, músicos que viviam anônimos pelos becos, pelos bares e pelas praças. Menos ambíguo, Lima 
Barreto, em uma circulação "chapliniana" pela cidade, também transita por bares, ruelas, cabarés, cortiços, trens e favelas tentando obter um perfil de uma cidade "que se quer ignorada" (VELLOSO, 1988, p.38).

As fotografias de Augusto Malta revelam a perseguição do sonho parisiense das avenidas, dos jardins, dos bulevares. Registra também a cidade que desaparece; os quiosques, sobrados coloniais, mercados, favelas, os morros tradicionais. As fotografias, para além de sua realidade, sugerem também uma impressão. Em meio ao caos da cidade em construção, dos desmontes, uma languidez se desprende da luz intensa transmitida nas imagens. Como se elas antecipassem certo desconforto urbano, uma eterna repetição dos movimentos de uma cidade às voltas com suas artérias e seus espaços sempre insuficientes. De uma cidade onde habitante e automóvel parecem irremediavelmente incompatíveis. Porém, em poucos anos a cidade atinge o status de "uma das mais belas do mundo".

Desconforto. Mal-estar. As cidades brasileiras, ao longo de sua constituição, têm recebido diferentes representações. "A praça venceu o engenho, mas aos poucos." A afirmação de Gilberto Freire (Op. cit.) dá a ideia da singularidade que implicou as nossas experiências urbanas. Transição sem rupturas. Florestan Fernandes (1960), em um estudo clássico sobre a cidade de São Paulo, identifica fragmentos da estrutura rural ibérica que foram transplantados para um outro ambiente geográfico, impedindo uma definição, como ocorria com as cidades ocidentais europeias, dos limites culturais entre vila e campo. Representações de cidades ocidentais, que a identificavam ao mercado ${ }^{4}$ e, inspiradas em uma lógica iluminista, como lugar de uma utopia civilizadora trazida pelo tempo da indústria, não parecem se adequar às imagens criadas para as cidades brasileiras na sua origem. Nessas cidades a experiência social urbana só "tardiamente se libertou de influências que operavam no sentido de manter elementos ou concepções característicos do antigo estilo de vida rural" (Op. cit., p.195). Sérgio Buarque de Holanda (1993) fala da natureza ibérica de nossas cidades e da sociabilidade que aí se constituía. A desagregação do mundo rural projetava-se como sombra sobre um mundo urbano ainda sem definição. O desmantelamento da herança ibérica não correspondia a uma "nova mentalidade" capaz de impulsionar um novo tempo e substituir antigas formas sociais. A passagem ao predomínio da cultura das cidades parecia ainda estar reiterando a imagem da cidade do "semeador", cuja configuração obedeceu menos a um planejamento racional de domar um território adverso e, sim, resultou de certo fazer aleatório baseado em uma rotina que a vida impunha.

A ideia de um mal-estar, expressa no "tom de inércia" presente em representações da cidade brasileira, era debitada à influência das nossas tradições ibéricas, que originaram cidades fragmentárias e eternamente incompletas, se comparadas a um modelo ocidental clássico. Mal-estar por sua fragilidade diante das exigências de acompanhar o tempo da modernidade. Cidades que teriam que se constituir em uma brevidade de tempo. LéviStrauss (1991), com um olhar estrangeiro, em uma comparação entre cidades americanas e europeias, revela sua perplexidade diante das "urbes fetais" do Novo Mundo. Na simultaneidade da frescura do novo e da decrepitude do velho tem-se a noção dos precoces estragos causados pelo tempo. Sessenta anos passados dessa impressão de Lévi-Strauss, Milton Santos (1990) constrói imagem semelhante. Falando da mesma cidade, São Paulo é vista como o melhor exemplar de uma cidade incompleta do Terceiro Mundo: "tudo 
que há de mais moderno pode aí ser encontrado, ao lado das carências mais gritantes". Se como metrópole industrial São Paulo representa anseios de desenvolvimento produtivo, "um farol de otimismo brilhando para o futuro", por um lado sua pobreza "nos recorda o fedor, a miséria e o desespero" das cidades do século XIX retratadas por Engels e Dickens (GOLDSMITH, 1994, p.26).

\section{A Cidade Desenvolvimentista}

O mito dos "bons tempos", que se inaugura com a década de 1950, vai progressivamente deslocar o papel das tradições ibéricas na constituição da metrópole, dando lugar a uma outra imagem da cidade sustentada em um projeto de crescimento e de modernização econômica: "a cidade desenvolvimentista" (CARVALHO, 1994, p.53).

Levando-se em conta a consideração de Carvalho (1994) de que a cidade desenvolvimentista seria a porta de entrada da temática das metrópoles contemporâneas no Brasil, a representação dessa cidade, que se constitui a partir de meados do século XX, remete para um novo conjunto de signos, imagens e experiências da vida social. Experiências que serão lidas de forma distinta pela imaginação criadora de artistas, por cientistas e outros produtores de representações.

Euforia. No cenário mundial pós-guerra, um clima de otimismo baliza as questões que fazem parte de uma agenda de práticas sociais, políticas e econômicas. No Brasil, o fim da era Vargas, os processos de industrialização e urbanização acelerada criam um sentimento de que essas transformações, de natureza política e econômica, forneceriam a credencial para um ingresso automático em uma modernidade democrática (Op. cit., p.57). A vontade da passagem de uma "velha" sociedade para uma "nova" era processada por uma mudança na orientação dos modelos estrangeiros. A imagem da cidade desenvolvimentista se constrói em uma projeção de novos modelos. Da tradicional ligação com o mundo lusíada e europeu, outros valores se constituem seguindo padrões americanos transmitidos principalmente pela propaganda publicitária de bens de consumo materiais e de estilos de vida, pelo consumo de bens simbólicos como o cinema e os livros (ORTIZ, 1992, p.71).

A imagem de uma "vida nova" foi uma forma da ideia desenvolvimentista. A esperança em uma vida nova se erigia como força indispensável ao dinamismo da vida social. O conforto, o bem-estar, os equipamentos domésticos, a indústria cultural. O consumo. A metrópole é a vitrine de um progresso técnico-científico e palco de produções culturais e intensas movimentações políticas. A arquitetura, as feiras industriais e exposições artísticas servem à divulgação de uma urbanidade a ser construída. Urbanidade fundada no valor do êxito da tecnologia. Nesse "tempo cultural acelerado", uma infinidade de signos se multiplica visando o consumo imediato: revistas de histórias em quadrinhos, como o Pato Donald, as fotonovelas, as radionovelas e teleteatros. Nos programas de auditório das rádios, reis e rainhas disputavam o cetro da música popular brasileira. Programas que tinham grande audiência nas camadas populares. Segundo Velloso (1991), a população encontrava nesse plano simbólico canais de participação. Os ídolos ofereciam aos seus fãs o mito da mobilidade social e da felicidade. As chanchadas da Atlântida, o "misto de show e comédia", também se aliava ao estado de espírito de "fé no futuro do Brasil". 
Sérgio Augusto (1989) dá uma mostra da chanchada como expressão de uma sociedade em trânsito para novos valores. "Nada de dramas atravessando o ritmo. Na passarela cinematográfica, só a alegria comandava o espetáculo." Alegria de uma sociedade que, embalada por um compasso de sambas e marchinhas, rumava para ingressar na era do consumo. Segundo Afrânio Catani e José de Melo e Souza (1983), a chanchada exprimia com fidelidade o "clima da época". A chanchada fazia a leitura, de forma satírica, de uma recente experiência urbana que configurava uma infinidade de problemas ligados à vida cotidiana, como, por exemplo, a carestia, o caos dos transportes na cidade, a falta d'água, o descalabro ecológico, amalgamados por "fantasias hollywoodianas" que misturavam signos de uma cultura estrangeira a elementos de uma cultura nacional, deixando, no dizer de Sérgio Augusto (1989), pouco espaço para que se realizasse uma crítica social e política mais profunda.

A imagem da cidade desenvolvimentista se construiria, assim, por oposição às representações do passado. No entanto, não tardou para que o desencanto com as ideias desenvolvimentistas poluíssem os projetos sonhados pela elite brasileira do período. A velha questão do "atraso versus modernidade" reaparecia em sua complexidade, esmaecendo a fachada eufórica que não conseguia disfarçar os problemas passados e as tensões de sempre. A narrativa do documentário Os anos JK (1980), de Silvio Tendler, mostra que em meio à ilusão de confiança, ao desejo de se internacionalizar e à vontade de se descobrir - foi a época da bossa nova, dos primeiros filmes do Cinema Novo, das bienais abstratas -, a modernidade alcançada não supera sua condição de disseminadora da injustiça social que se manifesta na voz e na ação insatisfeita, desesperada e por vezes resignada dos indivíduos.

Em Rio 40 graus (1955) e Rio Zona Norte (1958), realizações cinematográficas da década de 1950, podemos apreender uma outra cidade, que se contrapõe às imagens de alegria e euforia do período. Comparado aos filmes das chanchadas, está em vigência nessas produções do Cinema Novo uma nova forma de narrar a experiência urbana. Uma mentalidade mais crítica permeada por ideais de transformação social levava às telas uma realidade melancólica. Em Rio 40 graus, de Nélson Pereira dos Santos, a câmera que sobrevoa a cidade nos introduz de imediato na cidade cenário. A Baía de Guanabara, as praias da Zona Sul, o Pão de Açúcar, o Corcovado, o Maracanã. Até mesmo as favelas nos sugerem as imagens de cartão postal. Porém as belas imagens da exuberância natural de uma cidade dos trópicos, solar, dão lugar à representação da sociedade local por meio de personagens que vivem os pequenos dramas diários da sobrevivência. É mediante cinco meninos, vendedores de amendoim, que agora percorremos a cidade. ${ }^{5} \mathrm{O}$ morro, os pontos turísticos, as ruas da cidade adquirem um novo significado. São espaços em que as ações de segmentos sociais distintos vão revelando uma cidade de misérias, contradições e a permanente presença da violência nos gestos cotidianos.

Dois anos mais tarde, o mesmo diretor, em Rio Zona Norte, parece dar um tom mais pessimista a uma nova história. Distinto de Rio 40 graus - em que mesmo com as precárias condições de vida dos personagens a cidade ainda aparece como uma possibilidade, como um espaço em que, apesar das interdições sociais, ainda se consegue circular e nele ganhar a vida -, Rio Zona Norte não sugere mais a cidade ampla, de espaços por serem ocupados. A câmera agora está dentro da metrópole registrando o fluxo apressado 
de carros e transeuntes. A Central do Brasil, a linha férrea e o subúrbio são universos recortados de imediato. Na linha férrea está um corpo caído, do pingente Espírito da Luz, homem ingênuo, que, diante de uma cidade injusta, tenta transformar o cotidiano sonhando em ouvir seu samba interpretado na voz de Ângela Maria. É a partir dessa queda nos trilhos da estrada de ferro que Nélson Pereira dos Santos "faz desfilar as lembranças de Espírito da Luz", um sambista de morro "espoliado nas suas composições" por um inescrupuloso agente musical. A cidade que se constrói por meio da narração em retrospecto da vida de Espírito da Luz é uma cidade confinada, de deslocamentos previsíveis, de horizontes curtos e de tempo marcado, como sugere o relógio da Central do Brasil; uma cidade "negra, pobre, proletarizada", uma cidade oposta àquela "branca e civilizada" que vinha sento construída "desde o início e que o populismo e a ideologia desenvolvimentista corroboraram" (FABRIS, 1993, p.44).

A ideia de sonho desfeito criada por Brasília (1968), documentário de Joaquim Pedro de Andrade, serve como metáfora da trajetória dos ideais desenvolvimentistas. Brasília encarnava para a elite o tom que se queria dar ao país: "dinamismo, coragem, tenacidade, pioneirismo desbravador e audácia, fruto da vontade política associada ao espírito de aventura" (BOMENY, 1991. p.145). Símbolo daqueles tempos acelerados, que viria coroar uma ruptura com um "passado sonolento" e encarnar possibilidades de mudança social por meio de uma nova forma de organização urbana, a cidade de Brasília é, em Brasília, em um travelling delicado, porém contundente, desmistificada como o sonho de prosperidade e vida justa imaginado pelos planejadores e homens simples que a construíram.

Uma "era de certezas" e utopias modernas chega ao fim com o golpe militar de 1964. Ismail Xavier (1993), analisando algumas obras cinematográficas reproduzidas a partir do final da década de 1960, mostra como o cinema vai trabalhar em um diagnóstico da sociedade brasileira. A frustração com as expectativas de se construir uma experiência social próxima de uma "experiência-matriz mais plena", como aquela formulada pelos modelos europeus ou americanos, coloca novamente a ideia de "incompletude", da "falta", formulada agora na imagem do subdesenvolvimento, como o lugar de onde será construída uma representação da experiência urbana.

Macunaíma (1969), de Joaquim Pedro, talvez seja uma clara tradução, ou criação, de como aquela recente experiência insuflada pelo otimismo da crença no progresso "deu com os burros n'água". A partir da vivência de Macunaíma se apreende uma imagem da metrópole como "um mundo de Deus". Mundo fragmentado, heterogêneo, que dissolve as identidades para refazê-las a partir de uma outra lógica. Mundo de novos códigos, distintos do sertão, espaço inicial de Macunaíma. Mundo que reserva aos pobres que chegam nos "paus-de-arara" o desemprego, a mendicância, a prostituição, a vida dura da cidade. A relação de Macunaíma com a cidade se estabelece a partir de um choque com a "máquina", "a rua", a "burocracia", os "arranha-céus", a "multidão". A incompreensão primeira de Macunaíma sobre esse novo ambiente - marcado por uma relação homemmáquina que nos dá uma imagem da "desumanização" do meio urbano - se desfaz quando "num sábado à noite ele saca bem claro uma luz: os homens é que eram máquinas e as máquinas é que eram os homens da cidade" (Op.cit., p.144). A partir desse esclarecimento Macunaíma se "sente livre" para experimentar o jogo das relações reificadas da cidade - é a cidade como lugar da experiência da alienação uma das imagens 
apreendidas em Macunaíma. A liberdade de Macunaíma se traduz na forma "específica e positiva" que encontra de interação social. Macunaíma se integra na cidade a partir de um mundo marginal, e suas ações são orientadas pela "malícia do malandro", do "espertaIhão que tira partido de todas as oportunidades" e, desta forma, consegue "manejar as dificuldades e enfrentar o darwinismo social, o domínio do mais forte e o impulso explorador que domina todos os personagens". Segundo Ismail Xavier (1993), Joaquim Pedro havia encontrado na "devoração, a metáfora capaz de dar conta das relações sociais e das relações homem/máquina", ou melhor dizendo, Joaquim elege a "antropofagia como princípio de interação entre os personagens, regra básica da sociedade" e retorna, assim, à singularidade de uma experiência brasileira, pelo menos na que podia caracterizar aqueles anos que culminam na conjuntura de 1968. O desfecho do filme com a volta ao sertão e a morte de Macunaíma, em uma imagem verde-oliva e cor de sangue, pode ser lido na perspectiva de uma viagem sem retorno de uma urbanidade que fica a "meio caminho". Mas a cidade de Macunaíma é também uma cidade paradigma da cultura urbana que então se formava.

O Brasil do "milagre" que é construído pós-1968 veicula novas imagens. A referência ao "Brasil Grande" funciona como princípio legitimador do arbítrio e de regras de exceção (PÉCAULT, 1990, p.257). As classes urbanas mergulhadas no silêncio, marginalizadas ou submetidas a novos modos de consumo presenciam e participam da construção de uma urbanidade que, ao mesmo tempo em que se liga ao mundo pela emergência de instâncias comunicativas, com a criação de sistemas de telecomunicações e difusão de bens culturais, também vê aprofundar os sistemas de desigualdades.

A cidade brasileira, com sua complexidade e suas mazelas sociais cada vez mais evidentes e intoleráveis, se tornou um campo em que múltiplas abordagens disputam o entendimento desse intenso processo de interação entre grupos e segmentos diferenciados que dão o tom da vida na metrópole contemporânea. Em tempos mais recentes, algumas metrópoles têm sido exemplares dessa complexidade. A imagem do Rio como de uma "cidade partida" (asfalto-morro, pobres-ricos, ordem-desordem, cidadãos-novos bárbaros) frequentou os noticiários de tevê e da imprensa escrita. A "autorrepresentação estetizante" de cidade maravilhosa dos cartões postais e veiculadas por discursos oficiais concorre com os espetáculos da violência urbana divulgados pelos meios de comunicação. A ideia de uma experiência urbana dada pela "percepção de um estado de guerra permanente" atualiza, em uma escala ampliada, retratos benjaminianos de cidades em que a violência e a barbárie se sofisticam diante de uma sociedade em transe com seus próprios fetiches, de uma sociedade "erotizada em meio à paisagem do consumo".

\section{Cinema como Novo "Território"}

Diante da perspectiva de que a significação da metrópole atual não se limita a discursos que tinham como paradigma modelos e categorias da sociedade industrial, permanece a questão de como abordar o objeto cidade, visto as linhas segmentadas que vão conformando essa temática ao longo do tempo. De que cidade estamos, afinal, falando? Da cidade da fábrica, aquela cidade parte de um mecanismo, cidade que nos sugere uma "animação de máquina", da cidade da política, lugar em que se vivencia a barbárie da 
miséria, mas também se experimenta a possibilidade de igualdade e liberdade de que nos falava Marx e Engels, da cidade dos planejadores cujo fracasso é o fim do mito da cidade modernista ou da cidade fragmentada dos múltiplos signos, imagens e experiências da sociedade de informação, serviços e consumo? Como retirar a cidade de seu enquadramento tradicional, que supunha uma determinada base tecnológica que vem sendo superada nas últimas décadas, e colocá-la diante de novas lentes?

Sem pretender uma resposta e partindo de pistas sugeridas por Walter Benjamim de que a cidade do século $X X$ tem nas imagens produzidas pelos aparelhos de uma visão uma forma, por excelência de representação, o esforço aqui realizado foi o de construir um percurso que pudesse projetar alguma luz para o tratamento da cidade contemporânea no Brasil pensando em uma relação particular, a que se estabelece entre cinema e cidade. Assim, diante daquela perspectiva, arriscamos nos colocar frente a outras narrativas e indagar o que podem nos dizer as imagens acerca da experiência da metrópole. Ou, sendo mais específica: de que modo a experiência da urbanidade foi lida pelo cinema e de que forma essa pergunta pode ser articulada com o problemas das relação indivíduo e sociedade? Tal como Idriss, o menino muçulmano de La Goute D'Or que deixa o deserto em busca da sua fotografia feita por uma turista francesa, podemos também nos perguntar que representação o cinema fez da vida, da sociedade e da cultura da metrópole. O cinema percebido como um "novo" território, dotado de características sociais, geográficas e culturais próprias, em que símbolos e imagens aí apreendidos podem nos permitir, em um cotejo com fontes sociológicas, literárias e imagéticas, uma representação da metrópole nessa aurora de século. Compartilhando das idéias de Schwarz (1983) de que se a partir da forma, da primazia da organização sobre os elementos de conteúdo, a linguagem artística se distingue das demais, ela também permite o confronto ou mesmo a competição entre as linguagens e afirma-se enquanto uma dimensão de conhecimento da realidade.

\section{Referências Bibliográficas}

AUGUSTO, S. Este mundo é um pandeiro. São Paulo: Companhia das Letras, 1989.

ALMEIDA, M. A. Memórias de um sargento de milícias. Rio de Janeiro: Nosso Livro, [s. d.].

BARReTO, L. C. A. Clara dos Anjos 1.ed. [s. I]: Mérito, 1948.

BENEVIDES, M. V. O governo Kubitschek: a esperança como fator de desenvolvimento. In: Gomes, A. C. (org.). O Brasil de JK. Gomes. Rio de Janeiro: Editora da FGV/CPDOC, 1991.

BENJAMIM, W. Paris, capital do século XX e a Paris do Segundo Império em Baudelaire. Coleção Grandes Cientistas Sociais. São Paulo: Ática, 1985.

. A obra de arte na época de sua reprodutibilidade técnica. In: Luiz Costa Lima (org.). Teoria de cultura de massa. 4.ed. Rio de Janeiro: Paz e Terra, 1990. 
Martins, A. L. L.

BOMENY, H. Utopias de cidade: as capitais do Modernismo. In: Ângela de Castro Gomes (org.). O Brasil de JK. Rio de Janeito: Editora da FGV/CPDOC, 1991.

CARVALHO, M. A. R. Quatro vezes cidade. Rio de Janeiro: Sete Letras, 1994.

CATANI, A. M.; MELO SOUZA, J. I. A chanchada no cinema brasileiro. Coleção Tudo é História. São Paulo: Brasiliense, 1983.

ELIAS, N. A sociedade dos indivíduos. Rio de Janeiro: Zahar, 1994.

ENGELS, F. A situação da classe trabalhadora na Inglaterra. Rio de Janeito: Global Editora, 1986.

FABRIS, M. Nelson Pereira dos Santos: um olhar neo-realista? São Paulo: Editora da Universidade de São Paulo, 1994.

FERNANDES, F. Mudanças sociais no brasil. São Paulo: Difusão Europeia do Livro, 1960.

FREIRE, G. Sobrados e mucambos. v.1. Rio de Janeiro: José Olympio, 1985.

GOLDSMITH, W. São Paulo, cidade mundial: indústria, miséria e resistência In: KOVARICK, L. (org.). As lutas sociais e a cidade. São Paulo: Paz e Terra, 1994.

HARVEY, D. Condição pós-moderna. 4.ed. São Paulo: Edições Loyola, 1994.

HOGGART, R. As utilizações da cultura. 2 v. Porto: Editorial Presença,1975.

HOLANDA, S. B. Raízes do Brasil. 25.ed. Rio de Janeiro: José Olympio. 1993.

KOVARICK, L. (org.). As lutas sociais e a cidade. São Paulo: Paz e Terra, 1994.

LEVI-STRAUSS, C. Tristes trópicos. São Paulo: Perspectivas do Homem, 1991.

MARTINS, L. João do Rio, uma antologia. [s. I.]: Sábia; MEC, [s. d.].

MUNFORD, L. A cidade na História. São Paulo: Martins Fontes; UNB, 1992.

ORTIZ, R. A moderna tradição brasileira. 2.ed. São Paulo: Brasiliense, 1992.

PÉCAULT, D. Os intelectuais e a política no Brasil. São Paulo: Ática, 1990.

PRADO JR., C. Formação do Brasil contemporâneo. São Paulo: Brasiliense, 1971.

RIBEIRO, A. C. T. Metrópole e fragmentação: novos rumos na análise da modernização. In: Território, globalização e fragmentação. São Paulo: Hucitec, 1994. 
SANTOS, M. Metrópole corporativa fragmentada: o caso de São Paulo. São Paulo: Nobel, 1990.

SCHWARZ. R. Os pobres na literatura brasileira. São Paulo: Brasiliense, 1983.

SEVCENKO, N. A literatura como missão. São Paulo: Brasiliense, 1983.

TOURNIER, M. La Goutte D'Or. Paris: Gallimard, 1985.

VALLADARES, L. Le Petit Guide de la Recherche Urbaine au Brésil. Mimeo. Iuperj, 1988.

VELHO, G. Projeto e metamorfose. Rio de Janeiro: Zahar, 1994.

VELLOSO, M. P. As tradições populares na Bella Époque carioca. Rio de Janeiro: MEC; Funarte, 1988.

. A dupla face de Jano: Romantismo e Populismo. In: GOMES, A. C. (org.). O Brasil de JK. [s. I.]: FGV/CPDOC, 1991.

XAVIER, I. Alegorias do desenvolvimento. São Paulo: Brasiliense, 1993.

WEBER, M. Conceito e categorias da cidade. Fenômeno urbano. Rio de Janeiro: Zahar, 1976.

\section{FILMES:}

Tempos modernos (1936), Charles Chaplin.

Metrópolis (1926), Fritz Lang.

Os anos JK (1980), Silvio Tendler.

Brasília (1968), Joaquim Pedro de Andrade.

Rio 40 graus (1955), Nélson Pereira dos Santos.

Rio Zona Norte (1958), Nélson Pereira dos Santos.

Macunaíma (1969), Joaquim Pedro de Andrade. 
${ }^{1}$ Usando como mediadores experiências temporais e espaciais da vida social, Harvey tem como objetivo esclarecer vínculos entre processos culturais contemporâneos (pós-modernismo) e a transição do fordismo para a flexibilidade (cf. HARVEY, 1994, p.187). A referência nos interessa na medida em que a discussão remete a transformações das percepções humanas e da experiência da vida social na metrópole.

${ }^{2}$ É o caso da retomada do tema da modernização na década de 1990 como guia para se pensar características contemporâneas da sociedade brasileira. Noções tradicionais do pensamento social que remetem para a relação indivíduo e sociedade no contexto nacional, como a de "marginalização", "integração" e "exclusão", são revalorizadas. Tomam-se como indicadores dos impasses algumas temáticas e sínteses analíticas que se voltam para fazer um diagnóstico da sociedade atual, como, por exemplo, a apreensão da sociedade a partir de uma "ênfase isolada" nos "fenômenos expressivos de violência urbana", a qualificação do estado atual da sociedade pela "referência à moral e à ética" e pela adoção cada vez mais frequente das categorias "civilização e barbárie" para análise do estado da sociedade. Reconhece-se nesses casos uma apropriação muito restrita do instrumental analítico fornecido pela temática da modernização, como, por exemplo, os estudos sobre processos de inserção e de resistência cultural às normas sociais modernas. Por um lado, a abrangência analítica proposta na temática da modernização vem ao encontro de avanços obtidos na "compreensão multidimensional da sociedade, das múltiplas escalas de determinação e dos diferentes tempos que constroem concretamente a vida social", e por outro, estabelece contrastes com a orientação dos estudos atuais marcados pelo "contexto social imediato, e por relações configuradas pela temporalidade do cotidiano pela espacialidade do lugar". Relativiza-se, assim, a adesão da "noção de fragmentação" nos estudos contemporâneos de reconhecimento de processos sociais, fato que pode estar instituindo mecanismos culturais de implementação do fenômeno e informando percepções da realidade com ocultamento de referências concretas a processos históricos da sociedade brasileira. Essas reflexões encontram-se desenvolvidas no artigo de Ana Clara Torres Ribeiro, Metrópole e fragmentação: novos rumos na análise da modernização (p.143-53).

${ }^{3}$ As discussões de Norberto Elias em A sociedade do indivíduos informam sobre um tipo de debate no campo do pensamento social em que se colocam em discussão as dificuldades de relacionar conceitos tradicionais a formas de experiências contemporâneas e põe em perspectiva uma "sociologia dos processos" como abordagem do problema das relações indivíduo e sociedade, como "meio de expressar a experiência dos membros das sociedades mais complexas e individualizadas hoje existentes".

${ }^{4}$ Sobre a definição clássica de cidades no sentido econômico, ver Conceitos e categorias de cidade (Cf. WEBER, 1976).

${ }^{5}$ Mariarosario Fabris afirma que, embora a cidade ainda seja a grande protagonista, o "olhar neorrealista" de Nélson Pereira dos Santos dá "vez e voz a outros personagens: a gente do povo" (1994, p.82). 